\title{
Self-Organization of Nitrogen-Containing Polymeric Supramolecules in Thin Films
}

\author{
Matti Knaapila ${ }^{1}$, Mika Torkkeli ${ }^{2}$, Tapio Mäkelä ${ }^{3}$ Lockhart Horsburgh $^{4}$, Klas Lindfors ${ }^{1}$, \\ Ritva Serimaa ${ }^{2}$, Matti Kaivola ${ }^{1}$, Andrew P. Monkman ${ }^{4}$, Gerrit ten Brinke, ${ }^{5,1}$, Olli Ikkala ${ }^{1, *}$ \\ ${ }^{1}$ Department of Engineering Physics and Mathematics, Helsinki University of Technology, \\ P.O. Box 2200, FIN-02015 HUT, Espoo, Finland \\ ${ }^{2}$ Department of Physics, University of Helsinki, P.O. Box 9, FIN-00014, Helsinki, Finland \\ ${ }^{3}$ VTT Electronics, Microelectronics, Technical Research Centre of Finland, P. O. Box 1101, \\ FIN-02044 VTT, Espoo, Finland \\ ${ }^{4}$ Department of Physics, University of Durham, South Road, Durham, DH1 3LE, \\ United Kingdom \\ ${ }^{5}$ Materials Science Centre, Dutch Polymer Institute, University of Groningen, Nijenborgh 4, \\ 9747 AG Groningen, The Netherlands \\ *Corresponding Author: Email: Olli.Ikkala@hut.fi
}

\begin{abstract}
Rigid rod-like poly(2,5-pyridinediyl), semi-rigid polyaniline and flexible poly(4vinylpyridine) are nitrogen-containing polymers that with selected amphiphilic oligomers form self-organized comb-shaped supramolecules due to protonation, hydrogen bonding and polarnonpolar effects combined. Luminescent or conductive ordered structures are demonstrated in thin films. The structures are characterized using small-angle x-ray scattering (SAXS) and grazing-incidence small-angle $\mathrm{x}$-ray scattering (GISAXS). The uniformity is studied using atomic force microscopy and scanning near-field optical microscopy (SNOM).
\end{abstract}

\section{INTRODUCTION}

The electronic properties of conjugated polymeric materials can be tailored by selforganization [1], supramolecular self-organization [2,3] or supramolecular network formation [4]. These techniques $[5,6]$ provide nonlithographic tools to form nanoscale structures. The construction of the structures is, however, not always straightforward because of the rigid conformation of the backbone. Much can be learned from simple model systems of the kind presented here.

Polypyridines $[7,8]$ are remarkably stable and good electron transport materials that have a high photoluminescence quantum yield (PLQY) in the solid state. They allow preparation of efficient light-emitting devices [9]. In particular, poly(2,5-pyridinediyl) (PPY) is structurally among the simplest $\pi$-conjugated rigid polymers that contain specific sites needed to construct supramolecules and it can also be dissolved in selected solvents. These properties make PPY a natural choice to study the general aspects of supramolecules and their self-organization based on $\pi$-conjugated rigid polymers. Similarly, polyaniline (PANI) is one of the most practical conducting polymers due to its stability, processability and the cost-effectiveness of its synthesis.

Supramolecular structures of pyridine oligomers [10] or their polymeric modifications [11] have typically been based on coordination. Covalent bonding has been used to produce polypyridine-based hairy rods [12] and internal hydrogen bonding [13] to planarize the rings. There are versatile possibilities to structure semi-rigid PANI [14-17] and poly(4-vinylpyridine) (P4VP), a flexible nitrogen-containing polymer [18]. 
Because there are potential applications for PPY and PANI in photonics [9] and electronics [19], it is convenient to prepare their self-organized structures in the form of stable thin films that allow further manipulation of the materials, such as alignment. Films of conjugated polymers can also be further structured using lithographic patterning [20] or imprinting techniques [21]. Hexagonal structures of conjugated polymers can be prepared into freestanding thin films via polymerization [22] and plastized films via solution casting [23]. Multilayers of electroactive comb-shaped polymers [24] and conjugated wire-like structures [25] are prepared using Langmuir-Blodgett (LB) and deposition techniques [15]. Here, in contrast, spin-coating has been chosen keeping microelectronics applications in mind.

\section{EXPERIMENTAL DETAILS}

PPY was synthesized by dehalogenation polycondensation of 2,5-dibromopyridine with tetrakis-(triphenylphosphine)nickel(0) prepared in situ from reduction of $\mathrm{NiCl}_{2}$ by $\mathrm{Zn}$ in the presence of $\mathrm{PPh}_{3}$ in $N, N$-dimethylformamide. PPY consisted of a random mixture of head-tohead and head-to-tail units. $\mathrm{M}_{\mathrm{w}}$ of PPY, PANI, and P4VP were 6000 [26], 265000 [17, 27] and $50000 \mathrm{~g} / \mathrm{mol}$, respectively.

Complexes of PPY or PANI and camphorsulfonic acid (CSA), i.e. PPY (CSA) $)_{x}$, and PANI $(\mathrm{CSA})_{\mathrm{x}}$ were prepared by dissolving $\mathrm{x}$ moles of CSA vs. moles of polymeric repeat units in formic acid as $1 \mathrm{wt}-\%$ solutions. After mixing, the solvent was evaporated at room temperature and the complexes were dried. Complexes with 4-hexylresorcinol (HRES) and 5pentylresorcinol (PRES) were prepared similarly in dilute solutions of formic acid, followed by rapid evaporation and vacuum drying. Complexes with P4VP and methanesulfonic acid (MSA) and 3-n-pentadecylphenol (PDP) were prepared from methanol.

Grazing-incidence small-angle x-ray scattering (GISAXS) measurements were carried out using $\operatorname{CuK}_{\alpha}(\lambda=1.54 \AA)$ radiation from a sealed $\mathrm{x}$-ray tube. The beam was monochromatized with a Ni-filter and a totally reflecting glass block (Huber small-angle chamber 701). The transverse dimensions of the beam were reduced with slits to approximately $0.1 \times 0.5 \mathrm{~mm}^{2}$ at the detector. The intensity was measured using an image plate (IP) system from Molecular Dynamics. The distance between the sample and the detector was $90 \mathrm{~mm}$ and the pixel-size $88 \times 88 \mu \mathrm{m}^{2}$. The sample was mounted on a Huber goniometer and a translation table. The angle of incidence was ca. $0.2^{\circ}$. The films were spin-coated onto quartz substrates at typically 2000 rpm for $30 \mathrm{~s}$ from 1-3 wt-\% filtered solutions of formic acid. The size of the sample was ca. $1 \times 1$ $\mathrm{cm}^{2}$. Glancing-angle small-angle $\mathrm{x}$-ray scattering measurements were performed similarly using a reflection geometry above the critical angle. The beam size was $0.1 \times 4 \mathrm{~mm}^{2}$ at the sample and a linear one-dimensional proportional counter (Mbraun OED-50M) was used as the detector. Maximum error in the q-axis was ca. $5 \%$.

AFM experiments were performed using a Nanoscope III A instrument (Digital Instruments) operating in the noncontact mode.

Scanning near-field optical microscopy experiments were carried out using a modified commercial device from Topometrix (Aurora) in transmission geometry. The sample was excited with ca. $500 \mu \mathrm{W}$ of $457 \mathrm{~nm}$ light from a CW argon ion laser and the luminescence light was collected with an uncoated SNOM probe resulting in a spatial resolution of ca. $100 \mathrm{~nm}$.

PL spectra were measured using a charge coupled device (CCD) spectrograph following excitation at the peak of absorption by monochromated light from a $\mathrm{HgXe}$ lamp. 


\section{RESULTS AND DISCUSSION}

\section{Supramolecules}

PPY can be complexed with sulfonic acids that also tune the photonic properties [28]. On the other hand, the emeraldine base form of PANI can be converted to its conductive state by protonation, where typically sulfonic acids are used. When the acid molecule is amphiphilic, such as dodecylbenzenesulfonic acid (DBSA) [29], supramolecules are formed consisting of a polymer backbone complexed with DBSA molecules that form lamellar self-organized structures with alternating polar and nonpolar layers. The stoichiometric complexes are, however, not completely fluid-like probably due to the strong ionic attraction and strong repulsion. If the acid is not amphiphilic, such as methanesulfonic acid (MSA), but an additional amphiphile, such as octyl gallate i.e. 1-octyl-3,4,5-trihydroxybenzoate (OG) [30] or hexylresorcinol (HRES) [31], is hydrogen bonded, a mixture of PPY(MSA) and OG can be achieved which is a disordered (or isotropic) fluid at high temperatures, self-organized (or smectic-like) at lower temperatures and crystalline at room temperature [30]. The liquid crystalline state allows further manipulation, such as alignment of the material compared with crystalline polymer.

Particularly high PLQY of PPY is achieved when camphorsulfonic acid (CSA) is used. Also in the case of PANI, CSA is attractive as it yields the highest reported conductivity in solvent cast films. Therefore, CSA is an ideal component in the construction of PPY and PANI-based supramolecules. PPY(CSA) and PANI(CSA) are complexed with alkylresorcinols, where the bonding may involve the steric combination of physical interaction, as has been considered in the complexes between PANI(CSA) and resorcinol $[16,32]$. If the acid is selected to be CSA and the amphiphile is HRES, the PPY-based material is fluid-like down to lower temperatures than in the case of OG. PANI(CSA) complexes with HRES are only plasticized. The complex of P4VP and MSA becomes the organized form upon complexation with pentadecylphenol (PDP) [18].

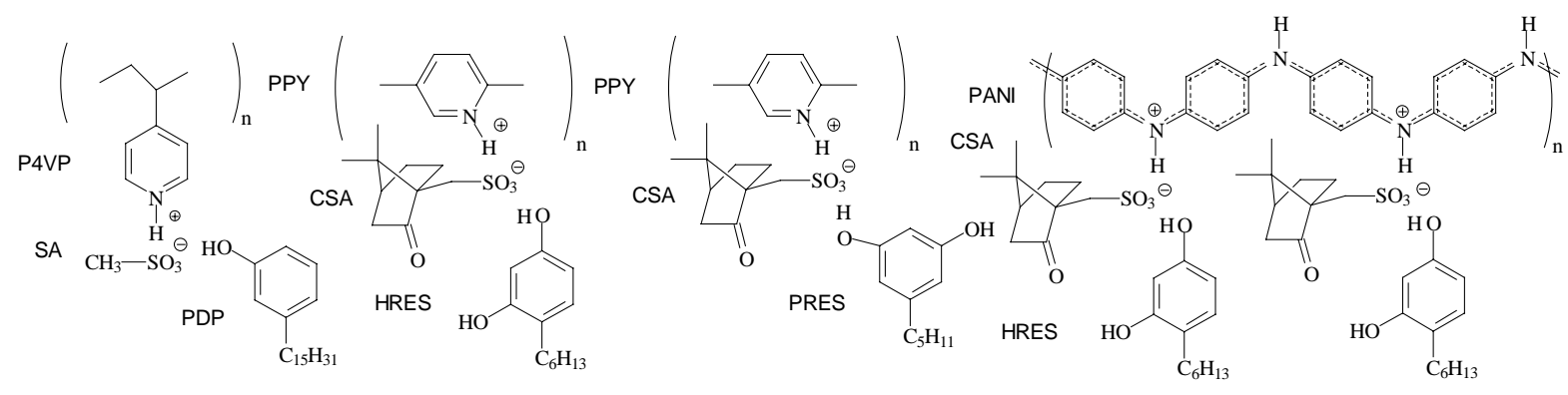

Figure 1. Schematics of proposed supramolecules that form self-organized structures.

\section{Self-organization in bulk material}

The self-organized structures of the mixture of P4VP(MSA) $)_{1.0}$ and PDP [18] and that of PPY(CSA) 0.5 and HRES are lamellar [31], and the structure of PANI(CSA) 0.5 and HRES is hexagonal cylindrical [17]. 


\section{$\underline{\text { Self-organization in thin films }}$}

The materials can be spin-coated from dilute solutions onto various substrates such as glass, quartz or silicon. Films are of good quality and homogeneous based on optical microscopy. The thicknesses are between 50 and $150 \mathrm{~nm}$ and the roughness of the surface ca. 3-15 nm as obtained from a $1 \mu \mathrm{m}^{2}$ sample area using atomic force microscope. PPY-based films are luminescent and PANI-based films conductive. If the former films are excited with UV-wavelengths of $340 \mathrm{~nm}$ or $365 \mathrm{~nm}$, a strong photoluminescence maximum in the range $500-550 \mathrm{~nm}$, and a smaller maximum at $400-450 \mathrm{~nm}$ are observed, which is typical for PPY-acid systems.

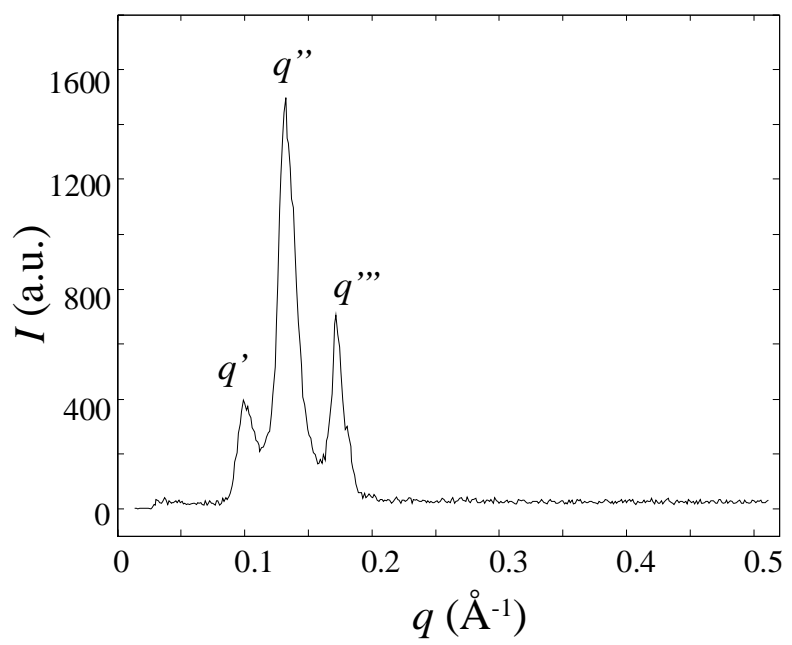

Figure 2. Glancing-angle scattering curve of the mixture of P4VP(MSA $)_{1.0}$ and PDP in the molar ratio $1.0: 1.0$ at $25^{\circ} \mathrm{C}$. Reflection $q$ ', indicates a structure with the long period of ca. $48 \AA$. Peaks denoted as $q^{\prime}$ and $q$," ' are due to the wave travelling along the surface and the wave reflected from the surface, respectively. The angle of the incident beam was ca. $1.2^{\circ}$.

The substrate and the thinness of the films practically prevent the transmission geometry of the small-angle x-ray scattering (SAXS). Instead, films can be studied using the glancing-angle geometry and Figure 2 shows one example. Because the position of the peak (q") equals that obtained from the bulk material, and because the film is homogeneous and none of the components of the complex shows a SAXS peak in this region, it is assumed that the observed structure corresponds to that in bulk. As the thickness of the film is, however, many decades smaller than that of the substrate, the scattering volume becomes very small and the background due to the substrate compared with the intensity of the diffraction increases strongly. Therefore, mesomorphic thin films are more generally studied using the grazing-incidence small-angle $\mathrm{x}$ ray scattering (GISAXS) method that combines both grazing-incidence geometry and detection at small-angles [1]. GISAXS experiments are performed at or near the angle of total reflection, which increases the x-ray path inside the film, whereas the background from the substrate remains low. Ideally, the angle of the incident beam is below the critical angle of the substrate but above to that of the surface of the mesomorphic film. As a result of this arrangement, the direct beam spillover, the displaced origin due to the refraction, the total reflection from the substrate and partially from the film surface, background due to the roughness of the surface and the proper reflections from the self-organized structure are obtained. 

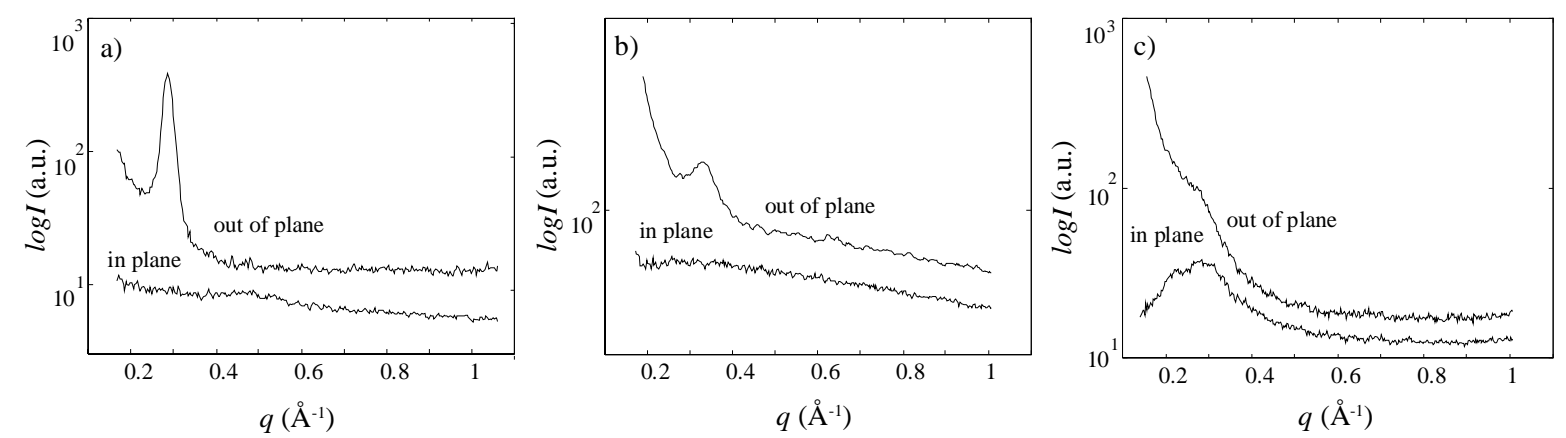

Figure 3. Azimuthally averaged GISAXS intensity from a $20^{\circ}$ sector around the sample normal (out of plane) and $20^{\circ}$ sector in the sample plane (in plane). (a) PPY(CSA) 0.5 and HRES in the molar ratio 1.0:0.5, (b) PPY $(C S A)_{0.5}$ and PRES in the molar ratio 1.0:0.5. (c) PANI $(C S A)_{0.5}$, and HRES in the molar ratio 1.0:1.0. The in plane -curves are slightly shifted for clarity. The incident beam angles were $0.4^{\circ}, 0.2^{\circ}$, and $0.1^{\circ}$, respectively.

Figure 3 shows results of GISAXS measurements performed using three different samples. In each case, a diffraction peak is observed suggesting that the structure formation occurs during the spin coating. Consequently, it is proposed that self-organization of the supramolecules takes place in thin films. The fact that a pronounced diffraction maximum of the PPY-based samples is seen perpendicular to the surface but not parallel to it suggests that the possible layers of the structures of PPY are aligned parallel to the surface (Figure 3a and 3b). The long periods agree with those in the bulk material, being ca. $21 \AA$ and $19 \AA$. For the sample in Figure 3 c, only a diffraction ring is obtained suggesting that the PANI-based structure has no preferred orientation onto plane. In this case, the structure is poorer and the long period differs from that of the bulk material (35 ̊) [17]. Therefore, the actual morphology in thin films remains open. The homogeneity of the PPY-based materials was studied using scanning near-field optical microscopy (SNOM). The near-field images show uniform emission from the sample with smooth surface topography. Evidence of phase separation was not observed. PL data of PPYbased material differs also from that of pure PPY, which indirectly indicates that the complexes are formed.

\section{CONCLUSIONS}

It is proposed that comb-shaped supramolecules of PPY, PANI, and P4VP can be selforganized in spin-coated thin films. These fluid-like or plastized ordered films are expected to allow further manipulation of the materials in contrast to the infusible crystalline polymers.

\section{REFERENCES}

1. H. Sirringhaus, P.J. Brown, R.H. Friend, M.M. Nielsen, K. Bechgaard, B.M.W. Langeveld-Voss, A.J.H. Spiering, R.A.J. Janssen, E.W. Meijer, P. Herwig, and D.M. de Leeuw, Nature 401, 685 (1999).

2. S. Ghosh, J. Rasmusson, and O. Inganäs, Adv. Mater. 10, 1097 (1998).

3. J.J. Apperloo, R.A.J. Janssen, P.R.L. Malenfant, L. Groenendaal, and J.M.J. Fréchet, J. Am. Chem. Soc. 122, 7042 (2000).

4. Reghu M., C.O. Yoon, C.Y. Yang, D. Moses, Paul Smith, A.J. Heeger, and Y. Cao, Phys. Rev. B 50, 13931 (1994). 
5. M. Muthukumar, C.K. Ober, and E.L. Thomas, Science 277, 1225 (1997).

6. M.C.T. Fyfe, and J.F. Stoddart, Acc. Chem. Res. 30, 393 (1997).

7. T. Yamamoto, T. Maruyama, Z-h. Zhou, T. Ito, T. Fukuda, Y. Yoneda, F. Begum, T. Ikeda, S. Sasaki, H. Takezoe, A. Fukuda, and K. Kubota, J. Am. Chem. Soc. 116, 4832 (1994).

8. J.W. Blatchford, S.W. Jessen, L.B. Lin, J.J. Lih, T.L. Gustafson, A.J. Epstein, D.K. Fu, M.J. Marsella, T.M. Swager, A.G. MacDiarmid, S. Yamaguchi, and H. Hamaguchi, Phys. Rev. Lett. 76, 1513 (1996).

9. S. Dailey, M. Halim, E. Rebourt, L.E. Horsburgh, I.D.W. Samuel, and A.P. Monkman, J. Phys.: Condens. Matter 10, 5171 (1998).

10. P. Baxter, J.-M. Lehn, A. DeCian, J. Fischer, Angew. Chem. Int. Ed. Engl. 32, 69 (1993).

11. S.S. Zhu, P.J. Carroll, and T.M. Swager, J. Am. Chem. Soc. 118, 8713 (1996).

12. C. Wang, M. Kilitziraki, J.A.H. MacBride, M.R. Bryce, L.E. Horsburgh, A.K. Sheridan, A.P. Monkman, and I.D.W. Samuel, Adv. Mater. 12, 217 (2000).

13. D.A.P. Delnoye, R.P. Sijbesma, J.A.J.M. Vekemans, and E.W. Meijer, J. Am. Chem. Soc. 118, 8717 (1996).

14. M.J. Winokur, and B.R. Mattes, Phys. Rev. B 54, 12637 (1996).

15. W.B. Stockton, and M.F. Rubner, Macromolecules 30, 2717 (1997).

16. O. Ikkala and G. ten Brinke, Handbook of Advanced Electronic and Photonic Materials and Devices 8, ed. H. Nalwa (Academic Press, 2000) pp. 185-208.

17. H. Kosonen, J. Ruokolainen, M. Knaapila, M. Torkkeli, K. Jokela, R. Serimaa, G. ten Brinke, W. Bras, A.P. Monkman, and O. Ikkala, Macromolecules 33, 8671 (2000).

18. J. Ruokolainen, R. Mäkinen, M. Torkkeli, T. Mäkelä, R. Serimaa, G. ten Brinke, and O. Ikkala, Science 280, 557 (1998).

19. C.J. Drury, C.M.J. Mutsaers, C.M. Hart, M. Matters, and D.M. de Leeuw, Appl. Phys. Lett. 73, 108 (1998).

20. N.L. Jeon, J. Hu, G.M. Whitesides, M.K. Erhardt, and R.G. Nuzzo, Adv. Mater. 10, 1466 (1998).

21. T. Mäkelä, T. Haatainen, J. Ahopelto, and H. Isotalo, Synth. Met. in press, (2000).

22. R.C. Smith, W.M. Fischer, and D.L. Gin, J. Am. Chem. Soc. 119, 4092 (1997).

23. U. Lauter, W.H. Meyer, and G. Wegner, Macromolecules 30, 2092 (1997).

24. M.N. Teerenstra, R.D. Klap, M.J. Bijl, A.J. Schouten, R.J.M. Nolte, T. Verbiest, and A. Persoons, Macromolecules 29, 4871 (1996).

25. J. Kim, S.K. McHugh, and T.M. Swager, Macromolecules 32, 1500 (1999).

26. L.E. Horsburgh, A.P. Monkman, and I.D.W. Samuel, Synth. Met. 101, 113 (1999).

27. P.N. Adams, P.J. Laughlin, A.P. Monkman, A.M. Kenwright, Polymer 37, 3411 (1996).

28. A.P. Monkman, M. Halim, I.D.W. Samuel, and L.E. Horsburgh, J. Chem. Phys. 109, 10372 (1998).

29. M. Jonforsen, S. Grigalevicius, M.R. Andersson, and T. Hjertberg, Synth. Met. 102, 1200 (1999).

30. O. Ikkala, M. Knaapila, J. Ruokolainen, M. Torkkeli, R. Serimaa, K. Jokela, L. Horsburgh, A. Monkman, and G. ten Brinke, Adv. Mater. 11, 1206 (1999).

31. M. Knaapila, J. Ruokolainen, M. Torkkeli, R. Serimaa, L. Horsburgh, A.P. Monkman, W. Bras, G. ten Brinke, and O. Ikkala, Synth. Met. in press, (2000).

32. T. Vikki, L.-O. Pietilä, H. Österholm, L. Ahjopalo, A. Takala, A. Toivo, K. Levon, P. Passiniemi, and O. Ikkala, Macromolecules 29, 2945 (1996). 